\title{
Meta-emotion: Tests of the Lutz hypothesis
}

\author{
WILLIAM N. DEMBER, RICHARD S. MELTON, DAO Q. NGUYEN, and STEVEN R. HOWE \\ University of Cincinnati, Cincinnati, Ohio
}

\begin{abstract}
This study tested the hypothesis, proposed by the anthropologist Catherine Lutz (1988), that emotion is devalued in Western culture (and hence in Western scientific psychology) relative to cognition, although it is valued over "estrangement." Alternate versions of an emotion versus cognition and an emotion versus estrangement questionnaire were developed using terms taken directly from Lutz or supplied by the authors; the questionnaire format was designed to match as literally as possible the wording of Lutz's argument. Each of 187 undergraduate students responded to one of the four questionnaires by indicating on thirty 10-point rating scales which of two anchor words (e.g., rational, irrational; masculine, feminine) was closer to the concept, cognition (as contrasted with emotion) or, in the alternate version, emotion (as contrasted with cognition); similarly, the subjects responded to one of two symmetrical versions of an emotion versus estrangement questionnaire. They also indicated which member of the pair of words defining each of the 30 scales was the more positive. The data were supportive of the Lutz hypothesis, both globally and with respect to most of the individual scales, and for both male and female subjects. There were also some interesting unexpected findings with regard to the questionnaire version.
\end{abstract}

It has been conventional to categorize the various emotions as positive or negative, implying that some emotions are "good" while others are "bad." Attaching evaluative connotations to psychological concepts seems an odd way to conduct science. Nevertheless, in the case of emotion, doing so seems to make intuitive sense, perhaps as a short-hand way of conveying the theoretical notion that emotions are responsive to, and hence indicative of, matches or mismatches between motives and goal states (see, e.g., Buck, 1985; Schefft, Moses, \& Schmidt, 1985). Thus, the so-called positive emotions are generated by a close match between what is wanted and what obtains, whereas the negative emotions signal a serious mismatch. In this view, emotions can be thought of as messengers, and we tend to praise or blame the messenger depending on whether the news is good or bad.

Emotions are subject to evaluation in a more insidious way. As a class, emotions have, in the history of Western philosophy and psychology, often been treated as inferior to cognitions. Indeed, emotions have been considered as disruptive of the smooth performance of linguistic utterances and complex motor skills (see, e.g., Spence, 1956) and, in Freudian theory in particular, as interfering with clear, logical, reality-based thinking and as distorting perception and memory. Beyond that, emotions can get one into trouble if they are permitted "to rule the brain" (Cook, 1971); they need to be restrained and moderated, to be brought under control. In short, by contrast with cognition, emotion tends to be treated as second class.

We would like to express our thanks to Louis Miller, Lynn Thesing, and Marae Martin for their assistance with data collection. Portions of this paper were presented at the meeting of the Eastern Psychological Association in April 1992 in Boston. Correspondence should be addressed to William N. Dember, Department of Psychology, University of Cincinnati, Cincinnati, OH 45221-0376.
The cultural anthropologist Catherine Lutz (1988), presents a well-articulated and persuasive argument that the view of emotion sketched above is endemic in Western (specifically, Northern European Protestant) philosophical, religious, and lay thinking and has thence entered Euro-American scientific psychology. To the extent that it does occur, the denigration of emotion within scientific psychology exemplifies an assertion most recently made by Riger (1992) that social science "reflects not only the values of individual scientists but also those of the political and cultural milieux in which science is done" (p. 730).

Lutz (1988) adds an interesting feminist twist by claiming that since women are considered the "emotional sex," their status is further diminished by this link to a negatively evaluated psychological process; other low-status groups (children, members of the lower class, and people in primitive societies) are similarly put down.

Lutz does acknowledge that within the Euro-American ethos, emotion is not all bad: When contrasted with what she terms "estrangement," emotion comes out the winner. Being alienated from others, detached, and emotionally unresponsive is worse even than being overly emotional.

To illustrate her dual hypothesis (by contrast with cognition, emotion is bad; by contrast with estrangement, emotion is good), Lutz (1988) offers a series of dimensions in which those contrasts can be made. For example,

Emotion is to thought as energy is to information, heart is to head, the irrational is to the rational, preference is to inference, impulse is to intention ... value is to fact ... the physical is to the mental, the natural is to the cultural ... the lower classes are to the upper, the child is to the adult, and the female is to the male. (pp. 56-57)

On the other hand, emotion can be viewed as good, as 
when emotion is associated with life, estrangement with death: "The warm, live person has the heat of emotions; the cold, dead one feels nothing on either side of the grave"' (p. 58).

Although Lutz's (1990) observations seem compelling, she provides only limited empirical support for them. It was the purpose of the present study to test her hypothesis as directly and literally as possible by asking people to respond to questionnaires containing the several dimensions that Lutz either explicitly or implicitly indicates will tap the biases that she postulates as dominant in our culture.

\section{METHOD}

\section{Subjects}

The subjects were 79 male and 108 female students from the introductory psychology pool who participated for course credit. The subjects were run in groups no larger than 12 by either a male or a female experimenter.

\section{Questionnaires}

The subjects were assigned at random to one of four questionnaires: two contrasted emotion and cognition; two contrasted emotion and estrangement. Responses were made on an Opscan answer sheet that afforded 10 options, 0 through 9 , for each questionnaire item.

The questionnaires had a common cover page tailored to the specific contrast facing the subject (emotion/cognition or emotion/estrangement). The opening paragraph of the questionnaire that contrasted emotion (as the focal concept) with cognition read as follows:

Scientific psychology makes use of many concepts that are taken from popular usage. Often these concepts have meanings or connotations that go beyond what is intended in their scientific usage. We are interested, in the present investigation, in the various ways that people evaluate the concept of EMOTION as it is contrasted with the concept of COGNITION. These terms are hard to define briefly, but generally EMOTION refers to the various feelings that people experience and express when things are going well or poorly for them, whereas cogNiTion refers to the thinking processes that people engage in when faced with a problem.

For the two questionnaires that dealt with the concept of estrangement, the following definition was provided: "ESTRANGEMENT refers to a lack of emotional response or emotional connection under conditions that might be expected to elicit emotion." Note that an effort was made to be as non-evaluative as possible in developing this definition.

As mentioned, there were two versions of the questionnaire that probed each of the two contrasts. In the case of the emotion/cognition (E/C) contrast, the focal concept for one questionnaire was EMOTION; for the other version (C/E), the focal concept was COGNITION. Similarly, for the emotion/estrangement contrast, the focal concept for one questionnaire (E/ES) was EMOTION, for the other questionnaire, it was ESTRANGEMENT (ES/E). The use of alternate versions of the two basic questionnaires was intended simply as a methodological nicety (although it turned out to matter in many scales in the emotion/cognition contrast). The number of subjects participating in each of the four conditions described above was, respectively, $51,42,48$, and 46 .

Consider subjects who were asked to focus on EMOTION and contrast it with COGNITION (i.e., subjects in the $\mathrm{E} / \mathrm{C}$ condition). Their task was to indicate whether, and to what extent, EMOTION (in contrast to COGNITION) is associated more closely with, say, irrational or rational, with superior or inferior, with masculine or feminine, and so on through a total of $\mathbf{3 0}$ scales. Nineteen of those scales contain terms taken directly from Lutz (1988), 7 were created by the authors to tap the same issues, and 4 were filler items that were not scored. The same format was used for the E/ES contrast, except that there were only 14 scales taken directly from Lutz; 8 scales were created by the authors, and there were 8 filler items. The order of the 30 scales constituting each pair of questionnaires (E/C and C/E; E/ES and ES/E) was randomly determined but fixed for all subjects. Similarly, whether the left or right pole of each scale was assigned a "positive" (e.g., rational) or "negative"' (e.g., irrational) term was randomly determined, but fixed for all subjects.

The terms "positive" and "negative" are in quotes to indicate that the evaluation was that of the authors, serving as interpreters of Lutz's (1988) argument. That is, we assumed, for example, that rational would be, for our subjects, more highly valued than irrational. However, in order to determine empirically which one of the terms defining the poles of each scale was considered preferable by the subjects themselves, they were asked, after completing the questionnaire, to go back to it and indicate "which one of the two words that define each of the scales you think is the more positive characteristic or association." The subjects responded by filling in the circle labeled A on the Opscan sheet if they thought that the word on the left-hand end of the scale was the more positive or the circle labeled $J$ if the word on the right-hand end of the scale was the more positive.

\section{RESULTS}

To facilitate the statistical analyses, scores for the subjects who completed the $\mathrm{C} / \mathrm{E}$ and the $\mathrm{ES} / \mathrm{E}$ questionnaires were first reversed. Second, scores for those specific pairs on any of the four questionnaires in which the emotion-laden term was the left pole were reversed. Throughout this paper, we always list the members of the pair with the emotion-laden term listed second even though this was not always true on the questionnaires. Finally, for each computation, all scores on all questionnaires were adjusted by subtracting 4.5 from them. The effect of all these transformations is that a positive rating always means that the emotionladen term was rated as being suggested by emotion.

With respect to the transformed ratings data, we were primarily interested in testing the null hypothesis that the mean rating for each pair of adjectives or nouns was equal to 0 (after subtracting 4.5 from each score). Based on Lutz's (1988) argument, we would expect that emotion would significantly more strongly suggest the negative terms on the cognition-emotion questionnaires and the positive terms on the emotion-estrangement questionnaires. We were also interested in the question of whether men and women would rate the pairs differently.

The means by sex and condition, as well as the grand means, for each pair of terms defining a scale on the emotion-cognition questionnaires are shown in Table 1. Three multivariate tests were performed. First, to test the multivariate null hypothesis that the mean rating was 0 for every pair, we calculated a one-sample Hotelling's $T^{2}$, which proved significant $\left(T^{2}=493.32, d f=26,67\right.$, $p<.001$ ). Second, to determine if men and women rated the pairs differently, we calculated a two-sample Hotelling's $T^{2}$, which resulted in a decision not to reject the null hypothesis of no difference $\left(T^{2}=45.34, d f=26,66\right.$, n.s.). Third, we calculated a two-sample Hotelling's $T^{2}$ to investigate the possibility that the two versions of the questionnaire might have resulted in different ratings and determined that there was, unexpectedly, a significant version effect $\left(T^{2}=294.56, d f=26,66, p<.001\right)$. Specifically, when emotion was the focal concept (E/C version), the Lutz hypothesis was not as strongly supported as when cognition was the focal concept (C/E version).

To investigate the implications of these multivariate results, we performed, separately for each pair, a two- 
Table 1

Means by Sex and Questionnaire Version of Ratings from the Emotion-Cognition Questionnaires

\begin{tabular}{|c|c|c|c|c|c|c|c|}
\hline & \multicolumn{2}{|c|}{$\mathrm{E} / \mathrm{C}$} & \multicolumn{2}{|c|}{$\mathrm{C} / \mathrm{E}$} & \multirow[b]{2}{*}{$\begin{array}{c}\text { Total } \\
(N=93)\end{array}$} & \multirow{2}{*}{$\begin{array}{c}\text { Test of } \\
\text { Grand } \\
\text { Mean }\end{array}$} & \multirow{2}{*}{$\begin{array}{l}\text { Test of } \\
\text { Version } \\
\text { Effect }\end{array}$} \\
\hline & $\begin{array}{c}\mathrm{M} \\
(n=24)\end{array}$ & $\begin{array}{c}\mathrm{F} \\
(n=27)\end{array}$ & $\begin{array}{c}\mathrm{M} \\
(n=20)\end{array}$ & $\begin{array}{c}\mathbf{F} \\
(n=22)\end{array}$ & & & \\
\hline Strong/weak & -0.54 & -0.20 & 1.50 & 1.82 & 0.55 & & $*$ \\
\hline Articulate/diffuse & -1.08 & 0.35 & 1.15 & 2.00 & 0.54 & & $*$ \\
\hline Mental/physical & -1.12 & -0.65 & 2.05 & 1.95 & 0.42 & & $*$ \\
\hline Superior/inferior & -1.12 & -0.83 & 1.55 & 2.23 & 0.33 & & $*$ \\
\hline Civilized/primitive & 0.00 & 0.31 & 2.65 & 2.36 & 1.22 & * & $*$ \\
\hline Clean/messy & 0.50 & -0.13 & 2.10 & 1.64 & 0.93 & * & * \\
\hline Rational/irrational & 1.08 & 0.65 & 2.45 & 3.59 & 1.84 & $*$ & $*$ \\
\hline Definite/uncertain & 0.54 & 0.09 & 1.85 & 2.55 & 1.17 & $*$ & $*$ \\
\hline Conscious/unconscious & 0.96 & -0.24 & 2.65 & 2.95 & 1.45 & $*$ & $*$ \\
\hline Directive/disruptive & 0.79 & 0.17 & 1.85 & 2.27 & 1.19 & $*$ & $*$ \\
\hline Order/disorder & 0.58 & 0.43 & 2.50 & 2.91 & 1.50 & $*$ & $*$ \\
\hline Mature/childlike & 0.58 & 0.46 & 1.95 & 2.86 & 1.38 & $*$ & $*$ \\
\hline Upper class/lower class & 0.00 & -0.83 & 1.45 & 1.68 & 0.47 & $*$ & $*$ \\
\hline Cold/hot & 2.71 & 2.43 & -0.15 & -0.50 & 1.25 & $*$ & $*$ \\
\hline Fact/value & 1.04 & 2.69 & 1.65 & 1.91 & 1.85 & $*$ & \\
\hline Sane/crazy & 1.50 & 0.28 & 1.95 & 2.09 & 1.38 & $*$ & \\
\hline Scientific/artistic & 2.54 & 3.09 & 2.35 & 2.23 & 2.59 & $*$ & \\
\hline Head/heart & 2.88 & 3.39 & 2.45 & 3.32 & 3.04 & $*$ & \\
\hline Stable/variable & 1.62 & 1.80 & 1.65 & 1.73 & 1.70 & $*$ & \\
\hline Information/energy & 2.21 & 2.83 & 1.55 & 2.45 & 2.31 & $*$ & \\
\hline Objective/subjective & 0.21 & 1.28 & 0.80 & 1.82 & 1.03 & $*$ & \\
\hline Intention/impulse & 2.38 & 2.39 & 1.05 & 2.55 & 2.13 & $*$ & \\
\hline Masculine/feminine & 0.71 & 1.65 & 1.65 & 0.14 & 1.05 & $*$ & \\
\hline Crisp/fuzzy & 1.21 & 1.20 & 1.50 & 1.68 & 1.38 & $*$ & \\
\hline True/worthy & 0.75 & -0.80 & 0.80 & 1.64 & 0.52 & & \\
\hline Cultural/natural & 0.25 & 0.83 & 0.50 & 0.41 & 0.51 & & \\
\hline
\end{tabular}

${ }^{*} p<.05$ (after Bonferroni adjustment).

between analysis of variance (ANOVA), with the independent variables being response set (with two levels) and sex (with two levels). ${ }^{1}$ In addition to determining if the main effects and the interaction were significant, we also determined if the grand mean was significantly different from zero. To control the experimentwise Type I error rate to .05 , a Bonferroni adjustment was performed. This procedure is appropriate for controlling the overall Type I error rate to $\alpha$ when the number of tests to be performed is known in advance (Dunn, 1961).

As shown in Table 1, the null hypothesis that the mean rating is 0 was rejected for 20 of the 26 pairs. In every case, the grand mean was greater than 0 . Taken together, these results represent very strong evidence in support of the Lutz hypothesis. There was no case of a significant sex effect and no case of a significant interaction involving sex and version of the questionnaire. There was, unexpectedly, a surprising amount of evidence that the response set itself influenced the ratings.

Table 2 presents the same analyses as shown in Table 1 , but for the emotion-estrangement questionnaires. Recall that a positive score indicates that the emotion-laden term was associated more with emotion than with estrangement. As before, three multivariate tests were performed. We determined that the mean rating was significantly different from zero $\left(T^{2}=384.16, d f=22,72, p<.001\right)$, that there was no overall difference in the ratings of men and women $\left(T^{2}=43.97, d f=22,71\right.$, n.s. $)$, and that there was a significant questionnaire version effect $\left(T^{\mathbf{2}}=\right.$ $121.08, d f=22,71, p<.001)$. Again, results in support of the Lutz hypothesis were not as strong when emotion was the focal concept (E/ES version) as when estrangement was the focal concept (ES/E version). Univariate ANOVAs were used to investigate the data further.

We again found strong support for the Lutz hypothesis; in this case, 19 of the 22 tests of the grand mean were significant, and the direction of the mean was again always as expected. As was true for the emotion-cognition questionnaires, there was never any sex effect or interaction between sex and questionnaire version. There were only two pairs for which the questionnaire version was significant, in contrast to the 14 found in analyzing data from the emotion-cognition questionnaires.

In addition to their ratings of which member of each pair was more evocative of emotion, recall that the subjects were also asked to state which member of the pair was the more positive. This task was the same regardless of which version of the questionnaire the subjects received. We asked two questions of these data. First, by using a normal curve test, we tested the null hypothesis that the overall proportion preferring one member of a pair over the other was .50. Our prediction, in keeping with the Lutz hypothesis, was that the term suggesting cognition would be the more preferred. Second, by using Fisher's exact test, we tested the null hypothesis that the proportions of men and women favoring a given term in a pair would be equal.

The results, again adjusted to control the experimentwise error rate at .05 , basically supported Lutz. In 18 of the 26 pairs, one term was preferred significantly over the other. In all but two of these 18 pairs (cold/hot and cultural/natural), the results were in the expected direction. 
Table 2

Means by Sex and Questionnaire Version of Ratings from the Emotion-Estrangement Questionnaires

\begin{tabular}{|c|c|c|c|c|c|c|c|}
\hline & \multicolumn{2}{|c|}{$\mathrm{E} / \mathrm{ES}$} & \multicolumn{2}{|c|}{$\mathrm{ES} / \mathrm{E}$} & \multirow[b]{2}{*}{$\begin{array}{c}\text { Total } \\
(N=94)\end{array}$} & \multirow{2}{*}{$\begin{array}{l}\text { Test of } \\
\text { Grand } \\
\text { Mean }\end{array}$} & \multirow{2}{*}{$\begin{array}{c}\text { Test of } \\
\text { Version } \\
\text { Effect } \\
\end{array}$} \\
\hline & $\begin{array}{c}\mathrm{M} \\
(n=16)\end{array}$ & $\begin{array}{c}\mathrm{F} \\
(n=32)\end{array}$ & $\begin{array}{c}\text { M } \\
(n=19)\end{array}$ & $\begin{array}{c}\mathrm{F} \\
(n=27)\end{array}$ & & & \\
\hline Cultural/natural & 1.50 & 1.81 & 0.08 & -0.02 & 0.88 & $*$ & $*$ \\
\hline Classic/romantic & 2.31 & 2.75 & 1.03 & 0.94 & 1.81 & $*$ & $*$ \\
\hline Logic/intuition & 1.94 & 1.34 & 1.13 & 1.17 & 1.35 & $*$ & \\
\hline Sterile/creative & 2.88 & 2.53 & 1.71 & 2.50 & 2.41 & $*$ & \\
\hline Inhumane/humane & 2.69 & 2.19 & 2.29 & 1.98 & 2.23 & $*$ & \\
\hline Vigor/enthusiasm & 1.38 & 0.81 & 0.76 & 1.13 & 0.99 & $*$ & \\
\hline Scientific/artistic & 3.12 & 2.44 & 1.18 & 2.09 & 2.20 & $*$ & \\
\hline Masculine/feminine & 0.31 & 1.78 & 2.08 & 1.54 & 1.52 & $*$ & \\
\hline Death/life & 2.44 & 0.81 & 1.87 & 1.87 & 1.61 & $*$ & \\
\hline Cold/hot & 1.44 & 1.25 & 1.97 & 2.28 & 1.72 & $*$ & \\
\hline Amorality/morality & 1.50 & 1.66 & 0.82 & 1.20 & 1.33 & $*$ & \\
\hline Individualism/relationship & 2.00 & 2.06 & 1.34 & 2.39 & 2.00 & * & \\
\hline Head/heart & 2.94 & 3.03 & 2.08 & 2.39 & 2.64 & $*$ & \\
\hline Constricted/free & 2.25 & 2.28 & 0.76 & 2.28 & 1.97 & $*$ & \\
\hline Bad/good & 1.56 & 1.28 & 1.66 & 1.61 & 1.50 & $*$ & \\
\hline Uncommitted/committed & 1.25 & 1.38 & 1.45 & 0.61 & 1.15 & $*$ & \\
\hline Alienation/attachment & 2.69 & 2.16 & 2.66 & 2.46 & 2.44 & $*$ & \\
\hline Contrived/authentic & 1.94 & 1.88 & 0.13 & 1.35 & 1.38 & $*$ & \\
\hline Businesslike/playful & 2.69 & 2.44 & 2.34 & 2.35 & 2.44 & $*$ & \\
\hline Objective/subjective & 0.94 & 0.34 & -0.13 & 0.17 & 0.30 & & \\
\hline Inferior/superior & 0.88 & 0.03 & -0.03 & 0.13 & 0.19 & & \\
\hline Crazy/sane & -1.12 & -0.28 & -0.08 & 1.35 & 0.09 & & \\
\hline
\end{tabular}

${ }^{*} p<.05$ (after Bonferroni adjustment).

For only one pair, masculine/feminine, was there a significant difference in the preferences of male and female subjects. As might be expected, the men preferred masculine, whereas the women preferred feminine.

Similar analyses for the 22 pairs on the emotionestrangement questionnaires revealed that in all but two pairs, the Lutz hypothesis was supported by evidence that the term suggesting emotion was preferred significantly more often than was the term suggesting estrangement. Interestingly, one of the two exceptions was masculine/ feminine, which was the only pair for which the preferences of the male and the female subjects were significantly different.

\section{DISCUSSION}

The present study approached the problem of empirically testing Lutz's hypothesis in two ways. The first approach involved determining which member of the pair of words defining each scale was the more evocative of emotion, whereas the second approach involved determining which member of each pair was regarded as the more positive. Overall, both approaches resulted in evidence confirmatory of Lutz's hypothesis. With respect to her argument that cognition is favored over emotion (see Table 1), the fact that all of the grand means are greater than zero (20 of them significantly so) means that the second member of the pair (e.g., primitive, messy, irrational) was more evocative of emotion. Moreover, in 16 of the 18 pairs in which one term was preferred significantly over the other, it was the cognitive term that was preferred. The evidence in support of her argument that emotion is preferred over estrangement is even more convincing. In 19 of the 22 scales shown in Table 2, the second member of the pair was considered more evocative of emotion than of estrangement, and the emotion-laden term was preferred significantly more often than was the term suggesting estrangement.

Since Lutz (1988) views the association of women and other low status groups with the concept of emotion as a cultural device for demeaning members of those groups, it is particularly important to note the resounding lack of any evidence that men and women differ in the extent to which certain terms are associated with emotion or that men and women differ in the perceived favorableness of terms associated with cognition over emotion (with a not very surprising exception being the pair masculine/feminine).

Recall that when the subjects were asked to evaluate cognition in contrast to emotion, the ratings tended to be more extreme than when they were asked to evaluate emotion in contrast to cognition. For example, cognition fell closer to the "strong" end of the strong/weak rating scale than emotion fell to the "weak" end. It seems that when emotion was the focal concept, the subjects' associations were not nearly as constrained by the Lutz (1988) bias as when cognition was focal. Thus, emotion, as a concept, may initially engage a much more diffuse and multivalent network of associations than does cognition. This kind of version effect, however, was not nearly so evident in the emotion-estrangement questionnaires, perhaps because, relative to cognition, the concept of estrangement has such a constricted and univalent network of associations, dominating the contrast with emotion regardless of questionnaire version.

\section{REFERENCES}

Buck, R. (1985). Prime theory: An integrated view of motivation and emotion. Psychological Review, 92, 389-413.

Cook, F. J. (1971, May 1). [Review of Diana: The making of a terrorist]. Saturday Review, p. 35.

DuNN, O. J. (1961). Multiple comparisons among means. Journal of the American Statistical Association, 56, 52-64.

LUTZ, C. A. (1988). Unnatural emotions: Everyday sentiments on a Micronesian atoll and their challenge to Western theory. Chicago: University of Chicago Press.

LuTZ, C. A. (1990). Engendered emotion: Gender, power, and the rhetoric of emotional control in American discourse. In C. A. Lutz \& L. Abu-Lughod (Eds.), Language and the politics of emotion (pp. 69-91). New York: Cambridge University Press.

Riger, S. (1992). Epistemological debates, feminist voices: Science, social values, and the study of women. American Psychologist, 47, 730-740.

Scheff, B. K., Moses, J. A., JR., \& SChmidT, G. L. (1985). Neuropsychology and emotion: A self-regulatory model. International Journal of Clinical Neuropsychology, 7, 207-213.

SPENCE, K. W. (1956). Behavior theory and conditioning. New Haven, CT: Yale University Press.

(Manuscript received on June 23, 1993.) 